\title{
Fluence and wavelength dependence of photoinhibition in the brown alga Dictyota dichotoma
}

\author{
Wilhelm Nultsch, Jürgen Pfau, Margarete Materna-Weide \\ Fachbereich Biologie der Philipps-Universität Marburg, Karl-von-Frisch-Straße, D-3350 Marburg 1, Federal Republic of \\ Germany
}

\begin{abstract}
Photosynthetic $\mathrm{O}_{2}$-production of Dictyota dichotoma was measured under constant conditions with an oxygen electrode after pre-illumination with light of different fluence rates and wavelengths. The extent of photoinhibition depends on both duration and fluence rates of irradiation, as well as on the wavelengths. The action spectrum shows photoinhibition maxima in the green (542 $\mathrm{nm}$ ) and red $(672 \mathrm{~nm})$, corresponding with the ranges of wavelengths absorbed by the xanthophyll fucoxanthin and the red band of chlorophyll $a$, respectively. Blue light is far less effective in proportion to its absorption by the chlorophyll $a$ and carotenoids other than fucoxanthin absorbing these wavelengths. Wavelengths above $700 \mathrm{~nm}$ absorbed only by PS I do not cause significant photoinhibition. These findings suggest that effective radiation is mainly absorbed by PS II. PS I seems not to be involved. If photoinhibited algae are transferred to light of low fluence rates, photosynthetic $\mathrm{O}_{2}$ production recovers fully within about $1 \mathrm{~h}$; in darkness full recovery is markedly delayed. The relatively fast recovery implies that photoinhibition in $D$. dichotoma is an adaptation to strong light exposure protecting the algae from photodamage.
\end{abstract}

\section{INTRODUCTION}

Excess light energy causes an inhibition of photosynthetic activity in plants, a phenomenon known as photoinhibition (Powles 1984). It is well known that during daytime the phytoplankton near the water surface is significantly photoinhibited, whereas photoinhibition decreases with increasing depth. Land plants also display photoinhibition. The extent of photoinhibition depends on several different factors. Shade plants show photoinhibition at lower fluence rates than sun plants (Powles \& Critchley 1980). Reduced atmospheric $\mathrm{CO}_{2}$ and $\mathrm{O}_{2}$ tensions increase the extent of photoinhibition (Powles 1984). Other environmental stress factors such as low temperature and water stress increase the extent of photoinhibition of land plants (Ögren \& Öquist 1984). Extremely high irradiances cause photodamage and, finally, oxidative death of the photosynthetic cells (Abeliovich \& Shilo 1972). Powles \& Critchley (1980) supposed that the electron flow through Photosystem II (PS II) is primarily affected. In addition Critchley \& Smillie (1981) demonstrated by in vivo fluorescence measurements that the site of photoinhibition is the oxidizing side of PS II, while PS I reac- tions are not inhibited. Contrary to these findings Barényi \& Krause (1985) suggested that the activities of both photosystems are affected by visible light. Harvey \& Bishop (1978) investigated photoinhibition in mutants of the green alga Scenedesmus obliquus. These authors postulated that the initial phase of inactivation caused by irradiation is located in PS I. Only prolonged illumination of the cells causes the disappearance of PS II activity.

In order to explain the molecular mechanism of photoinhibition, Ohad et al. (1984) correlated the in vivo turnover of the $32 \mathrm{kDa}$ protein (so called herbicidbinding-protein) to the extent of photoinhibitory damage in flagellate Chlamydomonas reinhardtii thylakoids. Matoo et al. (1984) postulated that the rate of breakdown of the $32 \mathrm{kDa}$ protein depends on the intensity of jllumination. Photoinhibition results from a rapid degradation of the $32 \mathrm{kDa}$ protein. Cleland \& Critchley (1985) suggested a different mechanism according to which a very efficient quencher is supposed to be generated by photoinhibition. This quencher may be a modified form of $Q_{A}$, a plastoquinone of PS II.

Action spectra of photoinhibition were not measured 
in the past. Nilson \& Danielson (1984) compared the photoinhibitory effects of only 3 different wavelengths. Most recently, Agel et al. (1987) investigated the wavelength dependence of photoinhibition in the cyanobacterium Anabaena variabilis in the range 411 to $711 \mathrm{~nm}$. Only radiation between 520 and $680 \mathrm{~nm}$ absorbed by the phycobiliproteins and short wave chlorophyll $a$ caused significant photoinhibition, whereas wavelengths $<520 \mathrm{~nm}$ were ineffective. Thus, for further discussions there was a need to determine the effects of different wavelengths for seaweeds also.

As shown by Nultsch et al. (1981), the photosynthetic activity of Dictyota dichotoma is strongly influenced by pre-illumination at high fluence rates but is independent of the chromatophore arrangement. The depression of the photosynthesis rate caused by high intensity irradiation was stronger in the red than in the blue, though red light is ineffective in causing the strong light arrangement of the phaeoplasts. Consequently, Zurzycki's $(1955,1975)$ hypothesis that the function of the chromatophore arrangement is regulation of photosynthetic activity does not hold true. Therefore, a more detailed study of photoinhibition in $D$. dichotoma seemed to be necessary.

\section{MATERIAL AND METHODS}

Dictyota dichotoma was cultivated in a modified Schreiber solution (without earth and organic matter). In order to increase the growth rate, the cultures, grown in white light under a $10: 14 \mathrm{~h} \operatorname{light}\left(3.78 \mathrm{~W} \mathrm{~m}^{-2}\right)$ : dark regime, were aerated. For pre-irradiation 'Prado' projectors (Leitz, Wetzlar, FRG) equipped with quartz iodine lamps were used. Fluence rates were varied by inserting neutral density filters. For light exposure, discs of $5 \mathrm{~mm}$ in diameter were cut out of the thallus and transferred to a small dish. The temperature during pre-irradiation was $15^{\circ} \mathrm{C}$. Monochromatic radiation was produced with the aid of interference filters (Schott, Mainz, FRG), with an average half-band width of $12 \mathrm{~nm}$. For the action spectrum of photoinhibition a constant photon fluence rate was used calculated on the basis of $10 \mathrm{~W} \mathrm{~m}^{-2}$ at $672 \mathrm{~nm}$. Measurements were repeated 6 times for each wavelength. One individual alga could be used only 3 times for measurements. The relative oxygen production of photosynthesis was measured with an oxygen electrode (Hydro Bios, Kiel, FRG) mounted in a seawater flow-through cuvette. The preirradiated alga was transferred into this cuvette. Natural seawater was used as flow-through medium and was held at a constant temperature of $15^{\circ} \mathrm{C}$. Red light of $1 \mathrm{~W} \mathrm{~m}^{-2}$ (672 nm SFK filter; Schott, Mainz, FRG) was used to measure photosynthetic oxygen production ('measuring light'). In order to study the recovery of photosynthetic activity in weak light, the algae were either kept in continuous measuring light for $60 \mathrm{~min}$, or exposed to a 5:5 min measuring light: dark cycle. Photoinhibition is expressed as $\mathrm{O}_{2}$-production by the alga in percent of the value measured before treatment.

The absorption spectrum was measured with a Shimadzu (Kyoto Japan) MPS 5000 recording spectrophotometer.

\section{RESULTS}

\section{White light experiments}

In a first series of experiments Dictyota dichotoma was pre-irradiated with white light of different fluence rates and exposure times. As expected, photoinhibition increased with the duration of illumination (Fig. 1). In principle, it is a relatively fast process. After $10 \mathrm{~min}$ of exposure $20 \%$ inhibition was measured, and almost $50 \%$ was reached after $30 \mathrm{~min}$.

Fig. 2 shows that photoinhibition, within certain limits, depends on the total fluence (fluence rate $x$ time) of pre-irradiation. Up to $40 \mathrm{~W} \mathrm{~m}^{-2}$, equal total

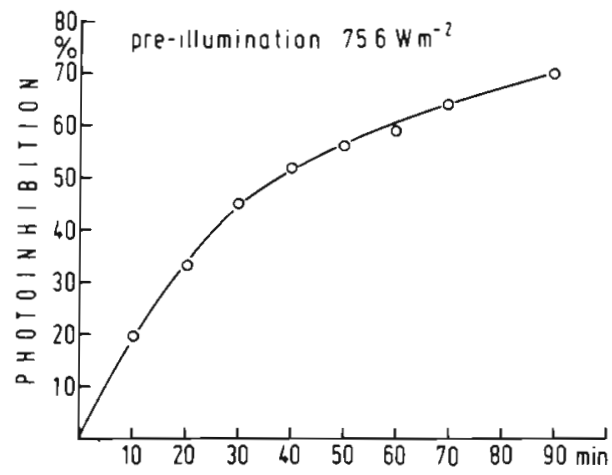

Fig. 1. Relative photosynthesis rate after different times of preillumination (75.6 $\mathrm{W} \mathrm{m}^{-2}$ ). Abscissa: time of pre-illumination; ordinate: photoinhibition in $\%$

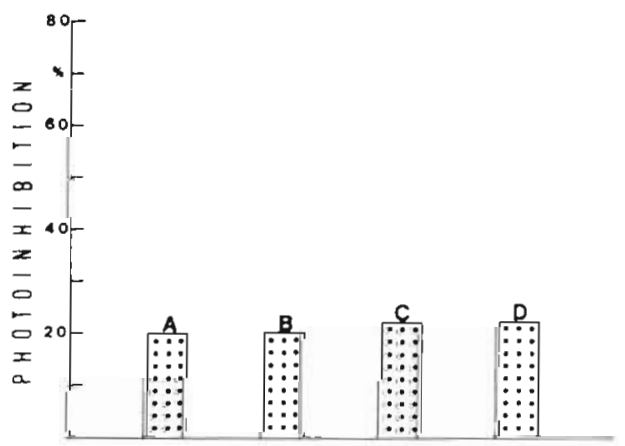

Fig. 2. Influence of fluence rate and duration of exposure on photoinhibition. White light was used for pre-illumination. A: $5.4 \mathrm{~W} \mathrm{~m}^{-2}, 240 \mathrm{~min} ; \mathrm{B}: 10.8 \mathrm{~W} \mathrm{~m}^{-2}, 120 \mathrm{~min} ; \mathrm{C}: 21.6 \mathrm{~W} \mathrm{~m}^{-2}$, $60 \mathrm{~min} ; \mathrm{D}: 43.2 \mathrm{~W} \mathrm{~m}^{-2}, 30 \mathrm{~min}$ 


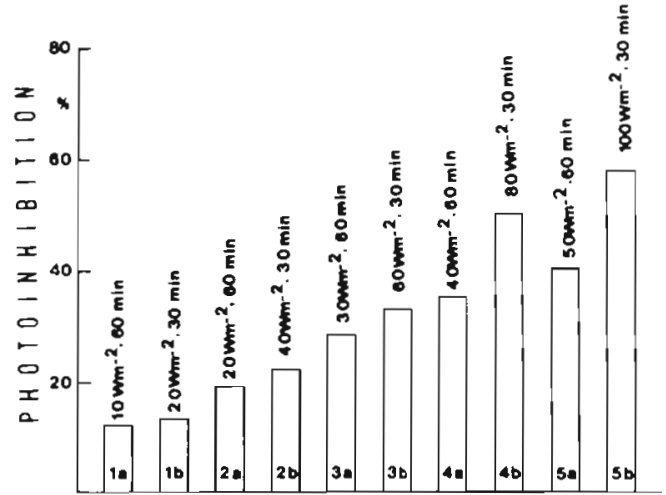

Fig. 3. Influence of fluence rate and duration of exposure on photoinhibition. White light was used for pre-illumination. Variation of exposure can be taken from the figure. Columns with the same number have the same total fluence

influences caused about the same extent of photoinhibition. However, above $40 \mathrm{~W} \mathrm{~m}^{-2}$ doubling the fluence rate caused greater photoinhibition than doubling the duration of pre-illumination (Fig. 3).

\section{Experiments with monochromatic light}

As mentioned above, action spectra of photoinhibition have been scarcely measured previously. In order to determine an action spectrum of Dictyota dichotoma, the thalli were exposed to monochromatic light of different wavelengths at a constant photon fluence rate


SFK filters were used, with half-band widths of about $40 \mathrm{~nm}$, since we did not have the means to produce radiation of sufficient high fluence rates with interference filters. For the same reason it was not possible to measure the action spectrum on the basis of fluence

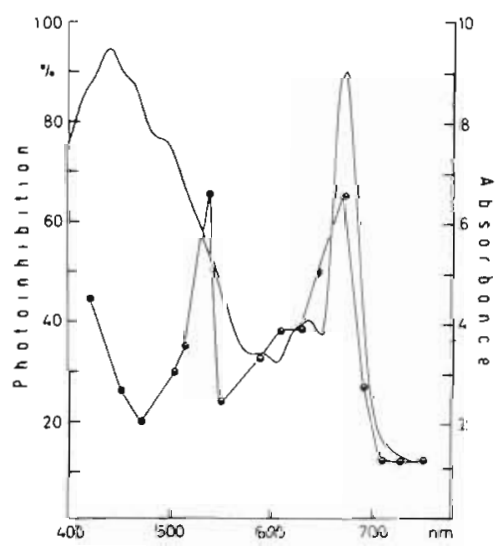

Fig. 4. Action spectrum of photoinhibition (•-•) and in vivo absorption spectrum $(-)$. Pre-irradiation: $(\bullet)$ SFK filters; $(\theta)$ interference filters, $56 \mu \mathrm{mol} \mathrm{m} \mathrm{m}^{-2} \mathrm{~s}^{-1}, 672 \mathrm{~nm}, 60 \mathrm{~min}$. Abscissa: wavelength in $\mathrm{nm}$, ordinates: photoinhibition in $\%$ and $a b$ sorbance rate-response curves. Fig. 4 shows the relative action spectrum of photoinhibition in comparison to the absorption spectrum of $D$. dichotoma. Nultsch et al. (1981) reported that in $D$. dichotoma depression of the photosynthesis rate caused by high fluence rates is stronger in the red than in the blue. This finding is confirmed by the present action spectrum. The lower effectiveness observed under blue light may be due to shading and/or photoprotection by carotenoids other than fucoxanthin, e.g. $\beta$-carotene. Wavelengths above $700 \mathrm{~nm}$ do not cause significant photoinhibitory effects. Thus, we may conclude that the photoinhibitorily effective radiation is absorbed mainly by PS II. PS I seems to be largely unaffected. In the range of radiation absorbed by chlorophyll $c$ (present only in small amounts) no significant stronger activity causing photoinhibition was detected compared to adjacent wavelengths. However, irradiation around $540 \mathrm{~nm}$ absorbed by the xanthophyll fucoxanthin, was about as effective in causing photoinhibition as that absorbed by the red band of chlorophyll $a$.

\section{Recovery of full photosynthetic activity}

If Dictyota dichotoma thalli are transferred from strong light back to weak light conditions, the photosynthetic activity recovers and, finally, reaches the initial level of oxygen production within about $1 \mathrm{~h}$. The kinetics of this recovery of photosynthesis depend on the wavelength of pre-irradiation, as shown in Fig. 5 for 2 different wavelengths: one strongly $(542 \mathrm{~nm})$ and one less effective $(691 \mathrm{~nm})$ in causing inhibition. Recovery of full photosynthetic activity took about $50 \mathrm{~min}$. Since pre-irradiation with the wavelength $542 \mathrm{~nm}$ was more effective than irradiation with $691 \mathrm{~nm}$, the values of $\mathrm{O}_{2^{-}}$ production are of course higher in the latter case.

A significantly delayed recovery, however, was observed in darkness. Therefore, the kinetics of recovery depend on the light-dark regime. This is shown in Fig. 6. The photosynthetic activity of thalli

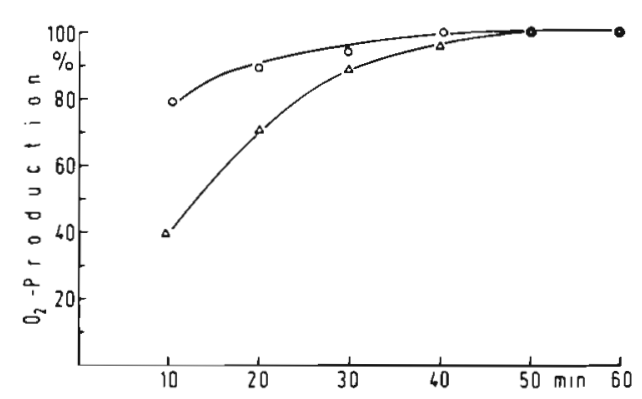

Fig. 5. Recovery of photosynthetic activity after pre-irradiation with $56 \mu \mathrm{mol} \mathrm{m}{ }^{-2} \mathrm{~s}^{-1}$. (১) $542 \mathrm{~nm}, 60 \mathrm{~min}$; (o) $691 \mathrm{~nm}, 60 \mathrm{~min}$. Measuring light: $672 \mathrm{~nm}, 1 \mathrm{Wm}^{-2}, 60 \mathrm{~min}$; light and darkness alternating every $5 \mathrm{~min}$ 
which were pre-irradiated under the same conditions recovered faster in continuous weak light $\left(1 \mathrm{~W} \mathrm{~m} \mathrm{~m}^{-2}\right.$, $672 \mathrm{~nm})$ than in a 5:5 min light $\left(1 \mathrm{~W} \mathrm{~m}^{-2}, 672 \mathrm{~nm}\right)$ : dark regime. The delay of recovery in darkness is shown in Fig. 7 . If the organisms were kept after pre-irradiation for $30 \mathrm{~min}$ in darkness, almost no recovery of photosynthetic activity could be observed.

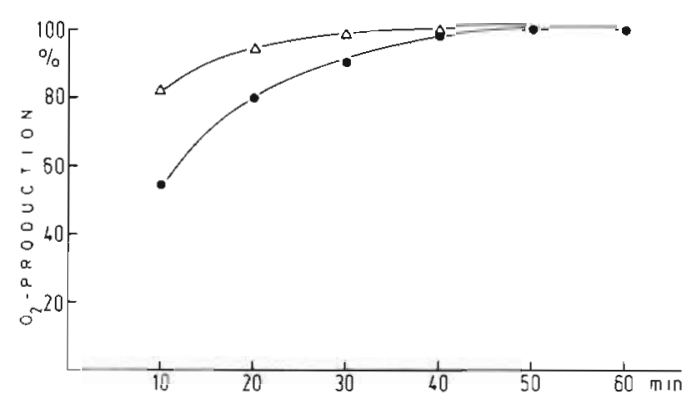

Fig. 6. Influence of different light conditions on recovery of photosynthesis. $(\Delta)$ Continuous measuring light of $1 \mathrm{Wm}^{-2}$, $672 \mathrm{~nm}, 60 \mathrm{~min}$. (•) Alternation of light $\left(1 \mathrm{Wm}^{-2}, 672 \mathrm{~nm}, 5\right.$ min) and dark (5 min)

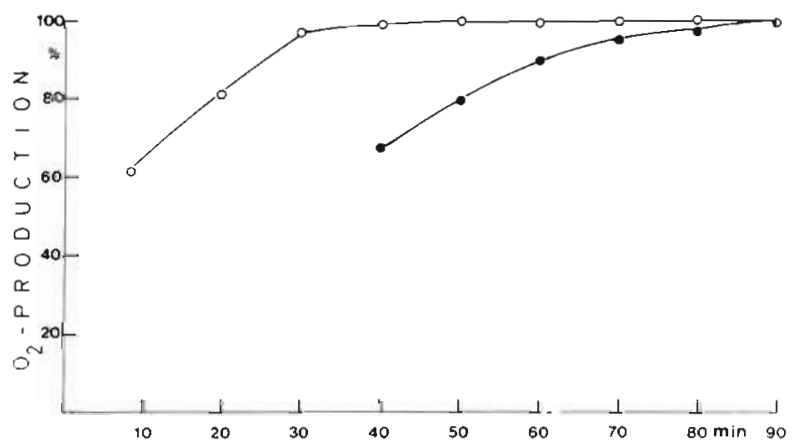

Fig. 7. Influence of darkness on recovery of photosynthetic activity. (•) Pre-illumination $43.2 \mathrm{Wm}^{-2}, 60 \mathrm{~min}$, white light. After exposure, the alga was kept for $30 \mathrm{~min}$ in darkness Measuring light: $672 \mathrm{~nm}, 1 \mathrm{Wm}^{-2}, 60 \mathrm{~min}$; light and dark alternating every $5 \mathrm{~min}$. First data of oxygen evolution could be measured after 40 min. (o) Restitution of photosynthesis rate after the same pre-irradiation. Measuring light: $1 \mathrm{Wm}^{-2}$, $60 \mathrm{~min}$, light and dark alternating every $5 \mathrm{~min}$

\section{DISCUSSION}

The extent of photoinhibition is a function of the duration of light exposure and the photon fluence rate. At fluence rates exceeding $40 \mathrm{~W} \mathrm{~m}^{-2}$ doubling the fluence rates is more effective than doubling the exposure time. Critchley \& Smillie (1981) stated that a light intensity 5 times higher than that used for cultivation is high enough to generate photoinhibition. It is remarkable that Dictyota dichotoma is photoinhibited by exposure to as little as $5 \mathrm{~W} \mathrm{~m}^{-2}$, i.e. only 1.3 -fold the light intensity used for cultivation. At an irradiance of $75.7 \mathrm{~W} \mathrm{~m}^{-2} 20 \%$ photoinhibition occurs within $10 \mathrm{~min}$.

In Lemna gibba, a water plant, Nilson \& Danielson (1984) reported that the depression of photosynthetic activity caused by monochromatic light at 446 and $662 \mathrm{~nm}$ was approximately equal, whereas photoinhibition at $704 \mathrm{~nm}$ was significantly less than at $662 \mathrm{~nm}$. In Dictyota dichotoma, however, blue light is much less effective than light of longer wavelengths in causing photoinhibition, as also observed by Agel et al. (1987) in the cyanobacterium Anabaena variabilis. The relatively small effect of the blue light may be due to shading and/or photoprotection by other carotenoids such as $\beta$-carotene. In both organisms, $A$. variabilis and $D$. dichotoma, red light absorbed by chlorophyll $a$ is strongly active. The high effectiveness of the range around $542 \mathrm{~nm}$ in $D$. dichotoma points to participation of the carotenoid fucoxanthin in perception of the active light. Light absorbed by PS I, e.g. wavelengths above $700 \mathrm{~nm}$, is almost ineffective. Thus, the hypothesis discussed in former reports that PS II is the site of photoinhibition is strongly supported for $D$. dichotoma by our action spectrum measurements.

Ohad et al. (1984) speculated that the turnover of the $\mathrm{Q}_{\mathrm{B}}$-protein (the so-called herbicid-binding-protein) is responsible for the extent of photoinhibition. According to this theory Matoo et al. (1984) proposed a regulation model for photoinhibition. They postulated that the 32 $\mathrm{kDa}$ protein is destroyed during high intensity irradiation, whereas it is synthesized again during recovery. This synthesis is light dependent. Ohad et al. (1984) observed in Chlamydomonas reinhardtii that photoinhibited chloroplasts recovered photosynthetic activity completely in weak light but only partially in darkness. In higher plants, Greer et al. (1986) found that the rate of recovery was substantially lower in darkness than in weak light. We observed similar effects in the marine alga Dictyota dichotoma. Darkness delayed the recovery of photosynthetic activity in comparison to continuous weak light irradiation. However, recovery depends also on the duration, the photon fluence rate and the light quality of pre-illumination. The rapid restitution of photosynthetic activity which takes place within $60 \mathrm{~min}$ points to the ecological importance of photoinhibition at least in this brown alga. Apparently, it is a protective mechanism from excess light energy rather than a photodamage. In this way, organisms are able to adapt to alterations of environmental light conditions relatively fast. Therefore, in future studies it would be of great interest to study photoinhibition of this alga in situ.

Acknowledgements. We are indebted to the Deutsche Forschungsgemeinschaft for financial support. 


\section{LITERATURE CITED}

Abeliovich, A., Shilo, M. (1972). Photooxidative reactions of C-phycocanin. Biochim. Biophys. Acta 283: 483-491

Agel, G., Nultsch, W., Rhiel, E. (1987). Photoinhibition and its wavelength dependence in the cyanobacterium Anabaena variabilis. Arch. Microbiol. 147: 370-374

Barényi, B., Krause, G. H. (1985). Inhibition of photosynthetic reactions by light. Planta 163: 218-226

Cleland, R. E., Critchley, C. (1985). Studies on the mechanism of photoinhibition in higher plants. II. Inactivation by high light of photosystem II reaction center function in isolated spinach thylakoids and $\mathrm{O}_{2}$ evolving particles. Photobiochem. Photobiophys. 10: 83-92

Critchley, C., Smillie, R. M. (1981). Leaf chlorophyll fluorescence as an indicator of high light stress in Cucumus sativus L. Aust. J. Plant Physiol. 8: 133-141

Greer, D. H., Berry, J. A., Bjorkman, O. (1986). Photoinhibition of photosynthesis in intact bean leaves: role of light and temperature and requirement for chloroplast-protein synthesis during recovery. Planta 168: 253-260

Harvey, G., Bishop, N. (1978). Photolability of photosynthesis in two separate mutants of Scenedesmus obliquus. Preferential inactivation of photosystem I. Plant Physiol. 62: 330-336

Mattoo, A., Hoffmann-Falk, H., Marder, J. B., Edelmann, M. (1984). Regulation of protein metabolism: coupling of photosynthetic electron transport and in vivo degradation of the rapidly metabolized $32 \mathrm{kDa}$ protein of the chloroplast membranes. Proc, natl Acad. Sci. U.S.A. 81: $1380-1384$

Nilson, S., Danielson, S. (1984). Photoinhibition of photosynthesis in Lemna gibba: the effect of $\mathrm{O}_{2}, \mathrm{CO}_{2}$ and the selective inhibition of PS II. J. Plant Physiol. 115: 39-48

Nultsch, W., Pfau, J., Rüffer, U. (1981). Do correlations exist between chromatophore arrangement and photosynthetic activity in seaweeds? Mar. Biol. 62: 111-117

Ögren, E., Öquist, G. (1984). Photoinhibition of photosynthesis in Lemna gibba as induced by the interaction between light and temperature. II. Photosynthetic electron transport. Physiol. plant. 62: 187-192

Ohad, J., Kyle, D. J., Arntzen, C. J. (1984). Membrane protein damage and repair: removal and replacement of inactivated 32 kilodalton polypeptides in chloroplast membranes. J. Cell Biol. 99: 481-485

Powles, S. (1984). Photoinhibition of photosynthesis induced by visible light. Ann. Rev. Plant Physiol. 35: 15-44

Powles, S., Critchley, C. (1980). Effect of light intensity during growth on photoinhibition of intact bean leaflets. Plant Physiol. 65: 1181-1187

Zurzycki, J. (1955). Chloroplast arrangement as a factor in photosynthesis. Acta Soc. Bot. Pol. 24: 27-63

Zurzycki, J. (1975). Adjustment processes of the photosynthetic apparatus to light conditions, their mechanism and biological significance. Pol. ecol. Stud. 1: 41-49

This article was submitted to the editor; it was accepted for printing on August 17, 1987 